\title{
Objective and Subjective Assessment of Physical Activity in Adults with Muscle Diseases
}

\author{
Erişkin Kas Hastalarında Fiziksel Aktivitenin Objektif ve Subjektif Değerlendirmesi
}

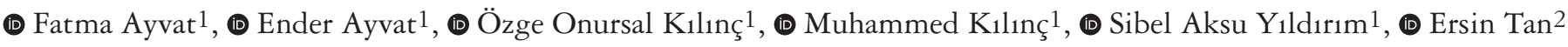
1 Hacettepe University Faculty of Health Sciences, Department of Physiotherapy and Rehabilitation, Ankara, Turkey

2Hacettepe University Faculty of Medicine, Department of Neurology, Ankara, Turkey

\begin{abstract}
Objective: The aim of this study was to investigate the physical activity of adults with muscle diseases relative to healthy controls.

Materials and Methods: Individuals participated in this cross-sectional study by completing the International Physical Activity Questionnaire-Long Form and using SenseWear Armband Activity Monitor over a 5-day period to assess physical activity levels subjectively and objectively.

Results: Forty healthy controls (16 males, 24 females) (aged 30.40 \pm 4.55 years) and 40 adults with muscle diseases (21 males, 19 females) (aged $32.67 \pm 6.57$ years) participated in this study. We found that SenseWear Armband (step counts, duration of moderate and vigorous physical activity) and International Physical Activity Questionnaire (walking physical activity, vigorous physical activity, working physical activity, and total physical activity) parameters were significantly lower in the adults with muscle disease group than the healthy controls $(\mathrm{p}<0.05)$, whereas the total amount of energy expenditure was similar between the groups $(\mathrm{p}>0.05)$.

Conclusion: Adults with muscle diseases expend the same amount of energy as healthy controls, but over fewer steps. This difference between energy expenditure and number of steps could be due to the higher energy requirements for walking in adults with muscle diseases. These findings will help healthcare professionals plan treatment strategies for adults with muscle diseases.
\end{abstract}

Keywords: Physical activity, chronic disease, energy expenditure

$\ddot{\mathbf{O} z}$

Amaç: Bu çalışmanın amacı, erişkin kas hastalarının fiziksel aktivitelerini sağlıklı bireylerle karşılaştırarak araştırmaktır.

Gereç ve Yöntem: Bu kesitsel çalı̧̧maya katılan bireyler, fiziksel aktivite düzeylerinin subjektif ve objektif olarak değerlendirilmesi için Uluslararası Fiziksel Aktivite Anketi-Uzun Versiyon'u tamamladı ve bireylere 5 gün boyunca SenseWear Armband Aktivite Monitörü takıldı.

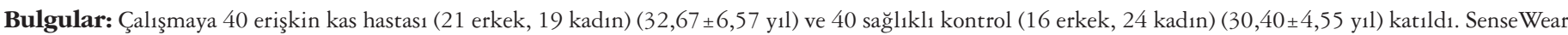
Armband'dan elde edilen adım sayısı, orta şiddetli fiziksel aktivite süresi ve şiddetli fiziksel aktivite süresi; Uluslararası Fiziksel Aktivite Anketi'nden elde edilen yürüyüş aktivitesi, şiddetli fiziksel aktivite, iş aktivitesi ve toplam fiziksel aktivite parametreleri erişkin kas hastalarında sağlıklı kontrollere göre anlamlı düzeyde düşük bulunurken $(\mathrm{p}<0,05)$; toplam enerji harcaması gruplar arasında benzer bulundu $(\mathrm{p}>0,05)$.

Sonuç: Sonuç olarak, erişkin kas hastaları sağlıklı kontrollerle daha az adım sayısında aynı miktarda enerji harcadılar. Enerji harcaması ve adım sayısı arasındaki bu fark, erişkin kas hastalarında yürümek için daha yüksek enerji gereksinimlerine bağlı olabilir. Bu bulgular, sağlık çalışanlarının erişkin kas hastaları için tedavi stratejilerini planlamasına yardımcı olacaktır.

Anahtar Kelimeler: Fiziksel aktivite, kronik hastalık, enerji harcaması

Address for Correspondence/Yazışma Adresi: Fatma Ayvat PT, Hacettepe University Faculty of Health Sciences,

Department of Physiotherapy and Rehabilitation, Ankara, Turkey

Phone: +90 5514252059 E-mail: fatma.avcu@ hacettepe.edu.tr ORCID: orcid.org/0000-0001-5692-4497

Received/Geliş Tarihi: 15.10 .2018 Accepted/Kabul Tarihi: 24.12 .2018

${ }^{\circ}$ Copyright 2019 by Turkish Neurological Society

Turkish Journal of Neurology published by Galenos Publishing House. 


\section{Introduction}

Physical activity (PA) is defined as any movement produced by skeletal muscles that results in energy expenditure (EE) above the basal level (1). PA is an important factor in the improvement of health and prevention of diseases. In individuals with physical and functional restrictions, PA is important because of the risk of a worsening of serious health problems (2). Individuals might adopt an inactive life because of tiredness, pain, contracture, breathing problems, exercise intolerance or progressive muscle weakness. Moreover, maintaining an inactive lifestyle increases the risk of secondary problems, such as coronary artery disease, obesity, osteoporosis, anxiety, and depression (3). Thus, it is particularly important to improve the PA level of adults with muscle disease (AwMD) (3).

Most studies related to the PA of AwMD groups have focused on pediatric muscle diseases $(4,5)$. A small number of the studies on AwMD have also shown that PA is affected more in the presence of neuromuscular diseases than in healthy individuals. McCrory et al. (6) found that the total EE of individuals with a neuromuscular disease was lower than in a healthy group because they spent less time doing PA and their EE was higher in very vigorous PA (VVPA). It is remarkable that almost all of the previous studies that included adult neuromuscular disease groups, such as those with neuropathy, myopathy or Charcot-Marie-Tooth diseases, were assessed in the scope of the same study. Factors such as symptoms, age at onset, affected body structure and functions, which can all directly affect PA, differ from one neuromuscular disease to another. Therefore, disease-specific measurements are likely to be more reliable.

Previous studies in this area were limited by some problems. For example, usually only an objective or subjective assessment method is applied (7), which has some disadvantages. For example, questionnaires are insufficient for assessments of sedentary activity levels, whereas measurements made using activity monitors reflect all PA levels but cannot identify the different PA types. Thus, there is a need for studies that assess PA in a comprehensive way with all of its parameters.

Here, we assessed the PA of an AwMD group relative to a matched healthy control (HC) group, including the number of steps, EE, time spent in PA of different intensities, and different PA metabolic equivalents (MET)-min/week values, using both objective and subjective methods.

\section{Materials and Methods}

\section{Participants}

This cross-sectional study was conducted at Hacettepe University, Faculty of Health Sciences, Department of Physiotherapy and Rehabilitation, between January 2016 and January 2017, after the necessary permission and approval was received from the university research ethics committee (Registration number: GO 14/617).

The study included 45 patients who were diagnosed as having muscle diseases by a neurologist, and 44 voluntary, healthy participants.

For the AwMD group, the inclusion criteria were: age between 20 and 40 years; diagnosed muscle disease; able to walk independently (not using assistive devices and able to walk independently for at least $500 \mathrm{~m}$ ). The exclusion criteria for the AwMD group were: systemic problems (e.g., diabetes mellitus or hypertension); surgery in the last 6 months; additional orthopedic problems that might affect PA performance; any serious neurologic diseases except the muscle disease; or have cognitive problems or co-operation difficulties.

For the HC group, the inclusion criterion was being aged between 20 and 40 years, and the exclusion criteria were any orthopedic and neurologic problems that might interfere with PA; systemic problems (e.g., diabetes mellitus or hypertension); and surgery in the last 6 months.

The study was explained in detail to the individuals who accepted to be included in the study, and informed consent forms were signed.

\section{Design}

The demographic characteristics of the individuals, such as age, height, weight, and body mass index (BMI) were recorded. Then, detailed information about the use of the SenseWear Pro 3 Armband (SWA) (BodyMedia, Inc., Pittsburg, PA, USA) activity monitor was given to all participants. The individuals were asked to wear the activity monitor on the triceps muscle of their right arm, and to remove it only during swimming and showering. The individuals were asked to put on the device as soon as they woke each morning, and they scheduled an appointment for 5 days later. All individuals in the study were asked to use the device for 5 days, which were planned as two weekend days and three weekdays. At the follow-up appointment, individual and anthropometric values were entered into the system, and the device was configured. Then, the data saved on the device were transferred to a computer using the SenseWear Professional Software (Version 8.1). The individuals were informed about the total number of steps, total EE, the daily number of steps and $\mathrm{EE}$, as well as time spent in PA of different intensities. The PA levels were also assessed using the International Physical Activity Questionnaires (IPAQ)-Long Form.

\section{Evaluations}

Subjective Assessment of Physical Activity Level with International Physical Activity Questionnaires-Long Form

The PA of the participants was subjectively assessed using the Turkish version of the IPAQ-Long Form (8). This questionnaire can be completed quickly and easily and assesses PA, which is classified according to its intensity. The questionnaire consists of 27 questions that address the duration the individuals spent on different physical activities during the last 7 days, seven questions address PA related to work, seven questions address transportation, six questions address housework, house maintenance, and caring for family, six questions address recreation, sports, and leisure time, and two questions address the time spent sitting on weekdays and the weekend (9).

Objective Assessment of Physical Activity Level with SenseWear Pro 3 Armband

The PA of the participants was assessed objectively using SWA (BodyMedia, Inc., Pittsburgh, PA, USA) multisensory activity monitors. The data were analyzed using the SenseWear Professional Software (Version 8.1) (10). 
The SWA is an activity monitor that includes multi-sensors, such as a galvanic skin response sensor to assess the electrical resistance differences of the skin, a heat flow sensor, and a skin temperature sensor to assess the heat change and consists of 2 axes. This variety of sensors give the device a high-level of sensitivity for detecting differences in EE related to complex life changes, which can be difficult to detect (11). While worn, the SWA constantly records and collects the physiologic state and movement information of the wearer (12). The system records the values of the individual, such as total EE, active EE, the total number of steps, duration in PA of different intensity, and sleep duration. The intensity of PA is classified according to MET cut-offs of 1.5-3 for light PA (LPA), MET 3-6 for moderate PA (MPA), MET 6-9 for vigorous PA (VPA), and MET $>9$ for VVPA (13). Studies conducted using the SWA have shown that this device shows the total EE, active EE, number of steps, duration of lying, sleep, and PA with greater than $90 \%$ accuracy (14).

\section{Statistical Analysis}

The data were analyzed using SPSS 20.0. The values are presented as the mean \pm standard deviation, number $(n)$, and percentage (\%). The normal distribution of the obtained data was evaluated visually (Histogram and probability plots) and using the Kolmogorov-Smirnov/Shapiro-Wilk tests. Nonparametric tests were used because the obtained data were not normally distributed. The independent samples t-test and chi-square test were used to determine the statistical significance of differences between the groups, and the Mann-Whitney $\mathrm{U}$ test was used to determine whether there were differences in terms of PA parameters. P values less than 0.05 were considered statistically significant.

The power of the study was calculated using the G*Power 3.0.10 analysis program. The SenseWear total number of steps results was used to determine the power of the study. Means, standard deviations, and sample sizes of groups were used to calculate the achieved power. According to these analyses, the study achieved a power of $98.32 \%$.

The data of volunteers who could not continue with the study were not included in the statistical analysis.

\section{Results}

\section{Demographics and Baseline Characteristics}

From an original 45 patients with AwMD and $44 \mathrm{HC}$ volunteers, nine were excluded. Forty adults with muscle diseases (12 myopathies, 2 distal myopathies, 5 muscular dystrophies, 6 limb-girdle muscular dystrophies, 6 facioscapulohumeral muscular dystrophies, 4 myotonic dystrophies, 4 Becker muscular dystrophy, and 1 inclusion body myositis) (21 males, 19 females) and 40 healthy individuals (16 males, 24 females) completed the study. A flowchart of the study is given in the Figure 1 .

The groups had similar age, height, weight, sex, and body mass index $(\mathrm{p}>0.05)$, but different occupational status $(\mathrm{p}<0.05)$ (Table 1).

SenseWear Pro 3 Armband: Objectively Assessed Physical Activity

Comparing the AwMD group and HC group using SWA, we detected a significant difference in the total number of steps, duration of MPA, and VPA ( $\mathrm{p}<0.05)$ (Table 2).

International Physical Activity Questionnaires: Subjectively Assessed Physical Activity

Comparing the weekly total PA findings, we found that the walking PA, VPA, total PA, and working PA of the AwMD group were significantly lower than for the HC group $(\mathrm{p}<0.05)$. No differences were found between the groups for MPA or other activity types ( $\mathrm{p}>0.05)$ (Table 3$)$.

\section{Discussion}

To our knowledge, this is the first original study to evaluate the PA of AwMD by both objective and subjective methods. We found that the AwMD group expended the same amount of energy as the matched HC group, but took fewer steps.

Several studies have investigated the daily average number of steps of individuals with neurologic diseases and pediatric individuals with muscle disease decreases $(5,15,16)$. Some studies reported a reduced number of steps by patients with AwMD, but none of these studies described the relationships

\begin{tabular}{|c|c|c|c|c|}
\hline & $\begin{array}{l}\text { AwMD Group } \\
\text { Mean } \pm S D \\
(n=40)\end{array}$ & $\begin{array}{l}\text { HC Group } \\
\text { Mean } \pm \text { SD } \\
(n=40)\end{array}$ & $\mathrm{t}$ & $\mathrm{p}$ \\
\hline Age (years) & $32.67 \pm 6.57$ & $30.40 \pm 4.55$ & 1.800 & 0.076 \\
\hline Height $(\mathrm{cm})$ & $170.35 \pm 9.36$ & $169.17 \pm 9.10$ & 0.569 & 0.571 \\
\hline Weight (kg) & $70.30 \pm 15.47$ & $65.80 \pm 13.48$ & 1.386 & 0.170 \\
\hline BMI $\left(\mathrm{kg} / \mathrm{m}^{2}\right)$ & $24.39 \pm 4.23$ & $22.81 \pm 2.81$ & 1.959 & 0.054 \\
\hline Sex (male/female) & $21 / 19$ & $16 / 24$ & & 0.502 \\
\hline Job status (employed/unemployed) & $21 / 19$ & $38 / 2$ & & $0.001^{* *}$ \\
\hline Onset of symptoms (months) & \multicolumn{4}{|l|}{$147.30 \pm 113.28$} \\
\hline Duration of the disease (months) & \multicolumn{4}{|l|}{$71.25 \pm 70.12$} \\
\hline Exercise behavior (present/absent) & \multicolumn{4}{|l|}{$32 / 8$} \\
\hline $\begin{array}{l}{ }^{*} \mathrm{p}<0.05 \text {, t-test, }{ }^{* *} \mathrm{p}<0.05 \text {, chi-square test } \\
\text { AwMD: Adults with muscle diseases, HC: Heal }\end{array}$ & 4 &. & . & \\
\hline
\end{tabular}




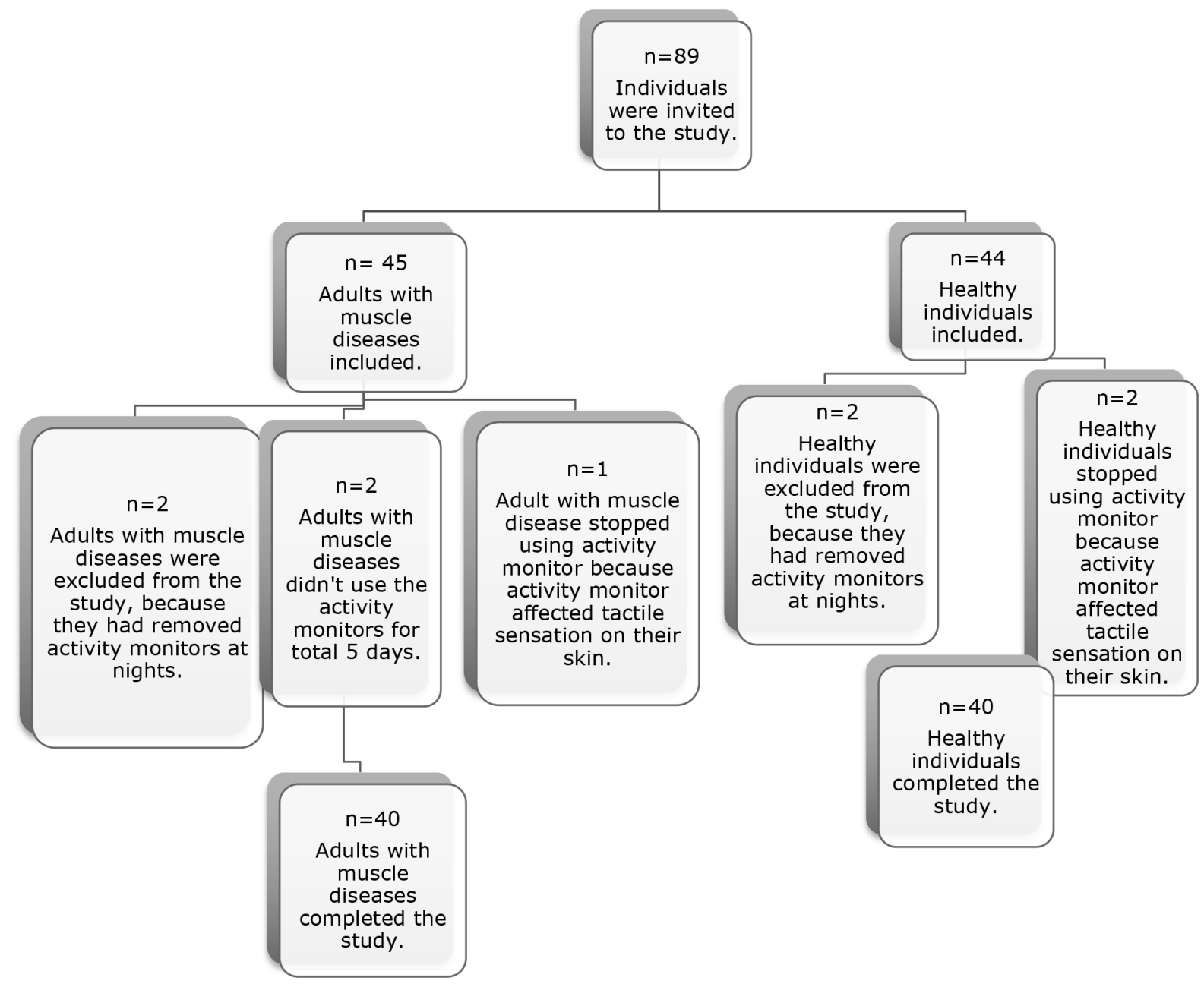

Figure 1. The flow chart of the study

between this situation and other PA parameters (17). Our finding that the AwMD group took fewer steps than the HC group was expected (7). The fewer steps but similar EE of the two groups can be accounted for by the AwMD group using more energy while walking (18). For example, individuals whose dorsiflexor muscles are weak try to minimize the risk of falling by making the steppage gait with the hip and knee flexion, thereby spending more energy (19). High levels of $\mathrm{EE}$ in muscle diseases have some risks. For this reason, while aiming to increase the number of steps, EE levels need to be controlled carefully. Thus, in this disease group, approaches for the protection and improvement of PA levels should be adopted by using energy protection techniques, such as the analysis and modification of the activities, balancing the working and resting time, determining the priorities in daily life activities (and modifying them), making effective use of the body, organizing the workplace, and using assistive technologies (20).

We found that the AwMD group spent less time in MPA and VPA than the HC group, whereas SPA, LPA, and VVPA durations were similar between the groups. In the PA guidelines published for healthy individuals, it was emphasized that it was necessary to do at least $150 \mathrm{~min}$ of MPA and 75 min of VVPA per week (21). Other studies have aimed to determine the weekly PA durations in different neurologic diseases and elder individuals $(22,23)$. There are no studies or PA guides stating the effects of different levels of exercises in the AwMD population (24). Lower VPA durations can be advantageous for individuals with muscle disease. This is because, in individuals with muscle disease, VPA can lead to damage to the continuity of the sarcolemma, thereby increasing the degeneration of muscle fibers (25). However, increasing the duration of MPA in AwMD should be one of the main aims of physiotherapists.

Using the IPAQ data, we found that the VPA level (MET$\mathrm{min}$ /week) was lower in the AwMD group than in the HC group, which is in line with our activity monitor findings. In addition, we found that total PA, walking PA, and working PA (MET-min/ week) values were lower in the AwMD group than in the $\mathrm{HC}$ group. Unlike SWA, the IPAQ MPA results did not differ between the $\mathrm{HC}$ and AwMD groups. We relied mostly on the SWA results when presenting our conclusions because the questionnaires 


\begin{tabular}{|c|c|c|c|}
\hline & $\begin{array}{l}\text { AwMD group } \\
\text { Mean } \pm \text { SD } \\
(\mathrm{n}=40)\end{array}$ & $\begin{array}{l}\text { HC group } \\
\text { Mean } \pm \text { SD } \\
(\mathrm{n}=40)\end{array}$ & $\mathrm{p}$ \\
\hline Total number of steps (number/5 days) & $29603.42 \pm 15720.30$ & $45680.62 \pm 18129.02$ & $0.0001^{*}$ \\
\hline Total EE (kcal) & $11431.50 \pm 3586.14$ & $11953.57 \pm 2692.42$ & 0.209 \\
\hline Total active EE (kcal) & $4856.42 \pm 3182.14$ & $4949.72 \pm 2253.40$ & 0.366 \\
\hline Total duration of SPA (min) & $5214.77 \pm 980.73$ & $5184.37 \pm 998.21$ & 0.700 \\
\hline Total duration of LPA (min) & $1224.52 \pm 766.92$ & $1221.17 \pm 919.18$ & 0.713 \\
\hline Total duration of MPA (min) & $286.27 \pm 28.95$ & $483.02 \pm 237.76$ & $0.0001^{*}$ \\
\hline Total duration of VPA (min) & $21.52 \pm 24.88$ & $52.22 \pm 52.47$ & $0.003^{*}$ \\
\hline Total duration of VVPA (min) & $0.37 \pm 0.80$ & $1.35 \pm 2.87$ & 0.359 \\
\hline \multicolumn{4}{|c|}{$\begin{array}{l}\text { "p }<0.05 \text {, Mann-Whitney U test } \\
\text { AwMD: Adults with muscle diseases, HC: Healthy controls, EE: Energy expenditure, SPA: Sedentary physical activity, LPA: } \\
\text { Light physical activity, MPA: Moderate physical activity, VPA: Vigorous physical activity, VVPA: Very vigorous physical activity, } \\
\text { SD: Standard deviation }\end{array}$} \\
\hline
\end{tabular}

Table 3. Subjective assessment-the International Physical Activity Questionnaires long form results of the adults with muscle diseases group and the healthy controls group

\begin{tabular}{|c|c|c|c|}
\hline & $\begin{array}{l}\text { AwMD Group } \\
\text { Mean } \pm \text { SD } \\
(n=40)\end{array}$ & $\begin{array}{l}\text { HC Group } \\
\text { Mean } \pm \text { SD } \\
(n=40)\end{array}$ & $\mathrm{p}$ \\
\hline Total PA (MET-min/week) & $3720.68 \pm 2650.19$ & $6177.56 \pm 4631.30$ & $0.027^{*}$ \\
\hline MPA (MET-min/week) & $1745.40 \pm 1806.50$ & $2522.00 \pm 2692.66$ & 0.319 \\
\hline VPA (MET-min/week) & $230.00 \pm 460.25$ & $845.00 \pm 1399.28$ & $0.010^{*}$ \\
\hline Walking PA (MET-min/week) & $1854.18 \pm 1611.91$ & $2810.77 \pm 2362.01$ & $0.047^{*}$ \\
\hline Working PA (MET-min/week) & $1254.08 \pm 2134.25$ & $3466.58 \pm 3254.97$ & $0.0001^{*}$ \\
\hline Transportation activities (MET-min/week) & $934.83 \pm 939.36$ & $987.11 \pm 1012.47$ & 0.754 \\
\hline Housework activities (MET-min/week) & $902.50 \pm 1258.47$ & $882.75 \pm 1155.37$ & 0.478 \\
\hline Leisure time activities (MET-min/week) & $794.26 \pm 814.42$ & $689.41 \pm 843.12$ & 0.277 \\
\hline Sitting duration (min) & $2523.00 \pm 908.41$ & $2258.25 \pm 789.64$ & 0.258 \\
\hline \multicolumn{4}{|c|}{$\begin{array}{l}\text { " } \mathrm{p}<0.05 \text {, Mann-Whitney U test } \\
\text { AwMD: Adults with muscle diseases, HC: Healthy controls, PA: Physical activity, MET: Metabolic equivalent, MPA: } \\
\text { Moderate physical activity, VPA: Vigorous physical activity, SD: Standard deviation }\end{array}$} \\
\hline
\end{tabular}

inadequately reflect non-vigorous (moderate and light) activities (26). On the other hand, the IPAQ assesses PA, which enabled us to investigate the PA of the AwMD group with greater detail. For example, in SWA, there is no separate parameter that assesses walking activity separately. This deficiency was compensated for by the IPAQ.

Our finding that participation in working activities is lower in those with AwMD than in HCs was expected because $95 \%$ of the HC group worked, whereas only $52.5 \%$ of the AwMD group were employed. It is important to enable the employment of the AwMD by directing them to professions appropriate for the severity of their disease (27). Increasing the PA of patients with AwMD decreases the risk of problems peculiar to their disease, as well as the development of secondary problems, such as coronary artery disease, obesity, osteoporosis, anxiety, and depression (3). Thus, increasing the PA of patients with AwMD would likely reduce healthcare costs (28).

\section{Study Limitation}

Including only those with AwMD who were able to walk is a limitation of our study. However, if we included patients with AwMD who could not walk, this would have introduced great variability in the PA levels of this group, making it difficult to generalize our findings.

\section{Conclusion}

We found that fewer steps were taken by a group of patients with AwMD than HCs. However, both groups expended the same amount of energy. According to this result, EE should also be considered while aiming to increase the number of steps of patients 
with AwMD. Compared with the HC group, we found that the AwMD group spent less time in MPA and VPA. Physicians should only attempt to increase MPA levels of patients because increased VPA is risky for patients with muscle disorders. Further work is required to investigate factors that lead to a decrease in PA in order to better understand the PA behaviors of patients with AwMD.

\section{Acknowledgments}

We acknowledge all patients with muscle disease and healthy participants.

\section{Ethics}

Ethics Committee Approval: Ethical approval was obtained from Hacettepe University Ethics Committee (date: 08.07.2015). The study protocol was performed in accordance with the Declaration of Helsinki.

Informed Consent: Written informed consent was received from each participant.

Peer-review: Internally peer-reviewed.

\section{Authorship Contributions}

Concept: F.A., E.A., S.A.Y., E.T., Design: F.A., M.K., E.T., Data Collection or Processing: F.A., Ö.O.K., Analysis or Interpretation: F.A., E.A., Literature Search: F.A., Ö.O.K., Writing: F.A., M.K., S.A.Y.

Conflict of Interest: The authors declare that they have no conflict of interest.

Financial Disclosure: This research did not receive any specific grant from funding agencies in the public, commercial, or notfor-profit sectors.

\section{References}

1. Caspersen CJ, Powell KE, Christenson GM. Physical activity, exercise, and physical fitness: definitions and distinctions for health-related research. Public Health Rep 1985;100:126-131.

2. Rimmer JH, Marques AC. Physical activity for people with disabilities. Lancet 2012;380:193-195.

3. McDonald CM. Physical activity, health impairments, and disability in neuromuscular disease. Am J Phys Med Rehabil 2002;81(11 Suppl):108-120.

4. Heutinck L, van Kampen N, Jansen M, de Groot IJ. Physical activity in boys with DMD is lower and less demanding compared to healthy boys. Neuromuscul Disord 2015;25:303-304.

5. Holtebekk ME, Berntsen S, Rasmussen M, Jahnsen RB. Physical activity and motor function in children and adolescents with neuromuscular disorders. Pediatr Phys Ther 2013;25:415-420.

6. McCrory MA, Kim HR, Wright NC, Lovelady CA, Aitkens S, Kilmer DD. Energy expenditure, physical activity, and body composition of ambulatory adults with hereditary neuromuscular disease. Am J Clin Nutr 1998;67:11621169.

7. Jimenez-Moreno AC, Newman J, Charman SJ, et al. Measuring habitual physical activity in neuromuscular sisorders: A systematic review. $\mathrm{J}$ of Neuromuscul Dis 2017;4:25-52.

8. Saglam M, Arikan $\mathrm{H}$, Savci $\mathrm{S}$, et al. International physical activity questionnaire: reliability and validity of the Turkish version. Percept Motor Skill 2010;111:278-284.
9. Craig CL, Marshall AL, Sjöström M, et al. International physical activity questionnaire: 12-country reliability and validity. Med Sci Sports Exerc 2003;35:1381-1395.

10. Scheers T, Philippaerts R, Lefevre J. Variability in physical activity patterns as measured by the SenseWear Armband: how many days are needed? Eur J Appl Physiol 2012;112:1653-1662.

11. Welk GJ, McClain JJ, Eisenmann JC, Wickel EE. Field validation of the MTI Actigraph and BodyMedia armband monitor using the IDEEA monitor. Obesity (Silver Spring) 2007;15:918-928.

12. Włodarek D, Głąbska D. Possibilities of using the sensewear mobile monitor in the assessment of the physical activity. Adv Sci Technol Res J 2013;7:3644.

13. Ainsworth BE, Haskell WL, Herrmann SD, et al. 2011 Compendium of Physical Activities: a second update of codes and MET values. Med Sci Sports Exerc 2011;43:1575-1581.

14. Liden CB, Wolowicz M, Stivoric J, Teller A, Vishnubhatla S, Farringdon J. Accuracy and reliability of the SenseWear ${ }^{\mathrm{TM}}$ armband as an energy expenditure assessment device. Body Media White Papers 2002.

15. Lord S, Godfrey A, Galna B, Mhiripiri D, Burn D, Rochester L. Ambulatory activity in incident Parkinson's: more than meets the eye? J Neurol 2013;260:2964-2972.

16. Sandroff B, Dlugonski D, Weikert M, Suh Y, Balantrapu S, Motl R. Physical activity and multiple sclerosis: new insights regarding inactivity. Acta Neurol Scand 2012;126:256-262.

17. Kilmer DD, Wright NC, Aitkens S. Impact of a home-based activity and dietary intervention in people with slowly progressive neuromuscular diseases. Arch Phys Med Rehabil 2005;86:2150-2156.

18. Bachasson D, Moraux A, Ollivier G, et al. Relationship between muscle impairments, postural stability, and gait parameters assessed with lowertrunk accelerometry in myotonic dystrophy type 1 . Neuromuscul Disord 2016;26:428-435.

19. Matjačić Z, Olenšek A, Krajnik J, Eymard B, Zupan A, Pražnikar A Compensatory mechanisms during walking in response to muscle weakness in spinal muscular atrophy, type III. Gait Posture 2008;27:661-668.

20. Mathiowetz VG, Finlayson ML, Matuska KM, Chen HY, Luo P. Randomized controlled trial of an energy conservation course for persons with multiple sclerosis. Mult Scler 2005;11:592-601.

21. Committee PAGA Physical activity guidelines advisory committee report. US Department of Health and Human Services, Washington, DC; 2008:114.

22. Nelson ME, Rejeski WJ, Blair SN, et al. Physical activity and public health in older adults: recommendation from the American College of Sports Medicine and the American Heart Association. Circ 2007;116:1094-1105.

23. Latimer-Cheung AE, Martin Ginis KA, Hicks AL, et al. Development of evidence-informed physical activity guidelines for adults with multiple sclerosis. Arch Phys Med Rehabil 2013;94:1829-1836.

24. Wright NC, Kilmer DD, McCrory MA, Aitkens SG, Holcomb BJ, Bernauer EM. Aerobic walking in slowly progressive neuromuscular disease: effect of a 12-week program. Arch Phys Med Rehabil 1996;77:64-69.

25. Tawil R, Van Der Maarel SM. Facioscapulohumeral muscular dystrophy. Muscle Nerve 2006;34:1-15.

26. Ara I, Aparicio-Ugarriza R, Morales-Barco D, Nascimento de Souza W, Mata E, Gonzáles-Gross M. Physical activity assessment in the general population; validated self-report methods. Nutr Hosp 2015;31(Suppl 3):211-218.

27. Minis MA, Kalkman JS, Akkermans RP, et al. Employment status of patients with neuromuscular diseases in relation to personal factors, fatigue and health status: a secondary analysis. J Rehabil Med 2010;42:60-65.

28. Jette AM, Keysor JJ. Disability models: implications for arthritis exercise and physical activity interventions. Arthritis Rheum 2003;49:114-120. 